\title{
选矿废渣煤䂥石烧结保温砖技术研究
}

杨晓玲

黑龙江省鸡西市生态环境局

DOI:10.32629/eep.v2i5.250

[摘 要] 本文针对选矿废渣煤矸石烧结保温砖技术,结合理论理论实践,在简要阐述选矿废渣煤矸石特性的基础上,分析了选 矿废渣煤矸石保温砖的影响,并提出选矿废渣煤矸石烧结保温砖技术的具体应用。分析结果表明,选矿废渣煤矸石来烧结保温 砖,既能缓减生态环境污染, 又能实现二次利用的发展理念,值得大范围推广应用。

[关键词] 选矿废渣; 煤矸石; 烧结; 保温砖

选矿废渣煤研石是煤矿资源挖掘、开采、洗煤过程中形 成的固体废弃物, 我国很多领域的发展依然离不开煤炭的支 持, 是目前全球第一产煤大国, 仅仅山西省选矿废渣煤䂥石 累积堆存量就超过 18 亿 $\mathrm{t}$, 长时间堆积不断会破坏土地资源, 污染生态环境, 而且都会周围居民的生活造成较大影响。选 矿废渣煤䂥石仍然具有良好利用前前景, 主要原因是其化学 性质黏土比较相似, 含有非常丰富的硅和铝资源, 可应用在 建筑工程前提保温砖烧结过程中, 对提升选矿废渣煤研石的 综合利用率有非常重要的意义。

\section{1 选矿废渣煤矸石特性}

第一, 选矿废渣属于典型的剥离式矿渣, 呈现淡黄色, 细 碎块状, 容重为 $1.36 \mathrm{~g} / \mathrm{cm}^{3}$, 天然含水量在 $9.2 \% \sim 9.5 \%$ 之间, 平均莫氏硬度为 1.45 左右。

第二, 煤矸石呈现黑色, 细碎块状, 容重为 $1.41 \mathrm{~g} / \mathrm{cm}^{3}$, 天然 含水量在 $9.1 \%$, 平均莫氏硬度为 1.38 , 属于典型的泥质材料。

第三, 污泥主要呈现灰色, 泥状, 容重为 $1.43 \mathrm{~g} / \mathrm{cm}^{3}$, 天然 含水量比较高, 在 $20.1 \% \sim 24.6 \%$ 之间, 平均莫氏硬度为 1.02 左右。

\section{2 选矿废渣煤矸石对保温砖性能的影响}

2.1 粒径对保温砖性能的影响

按照选矿废渣煤䂥石和膨润土以 $1: 1$ 比例混合, 成型压 力为 $12 \mathrm{MPa}$, 在 $950^{\circ} \mathrm{C}$ 下, 烧结 1 小时, 发现选矿废渣煤䂥石粒 径对保温砖性能的影响如表 1 所示:

表 1 选矿废渣煤䂥石粒径对保温砖性能的影响

\begin{tabular}{|c|c|c|c|c|}
\hline 粒径/目 & 保温砖外观 & 抗压强度 $/ \mathrm{MPa}$ & 导热系数 $/ \mathrm{W} /(\mathrm{m} \mathrm{K})$ & 体积收缩率 $/ \%$ \\
\hline $10^{\sim} 20$ & 大裂缝, 掉粉 & 1.60 & 0.27 & 2.6 \\
\hline $20 \sim 40$ & 大裂缝, 掉粉 & 1.65 & 0.32 & 3.4 \\
\hline $40 \sim 60$ & 小裂缝, 微掉粉 & 4.66 & 0.34 & 4.5 \\
\hline $60 \sim 80$ & 无裂缝, 不掉粉 & 8.26 & 0.36 & 4.9 \\
\hline $80^{\sim} 100$ & 无裂缝, 不掉粉 & 8.95 & 0.38 & 5.2 \\
\hline
\end{tabular}

选矿废渣煤矸石中含有大量有机物, 在高温持续烧结过 程中, 这些有机物会发生不同程度的物理变化, 在砖体内部 形成孔洞, 降低保温砖的导热系数, 尺寸发生不同程度收缩。 表 1 中可以看出, 选矿废渣煤䂥石的粒径鳄鱼小, 裂纹逐步 消失, 掉粉现象也到了有效解决, 体积收缩率变大, 抗压强度 明显增加, 导热系数也随之变大。因此, 在选矿废渣煤矸石烧
结保温砖时, 要尽量选择较细的粉料, 并保证粉料搅拌的均 匀性, 提升可塑性和实际结合能力, 避免发生爆裂现象。但粒 径超过 60 目时, 烧结的保温砖外观良好, 抗压强度和导热系 数 的变化也比较小, 可降低成本消耗量, 因此, 具体烧结保 温砖时可采用粒径在 $60 \sim 100$ 目的选矿废渣煤矸石。

\section{2 掺量对保温砖性能的影响}

利用选矿废渣煤䂥石烧结保温砖是目前充分利用选矿 废渣煤研石的主要途径, 需要在满足保温砖性能的基础上, 尽量提升选矿废渣煤䂥石的利用率, 研究表明, 选矿废渣煤 研石掺量对烧结保温砖性能的影响如图 1 所示:

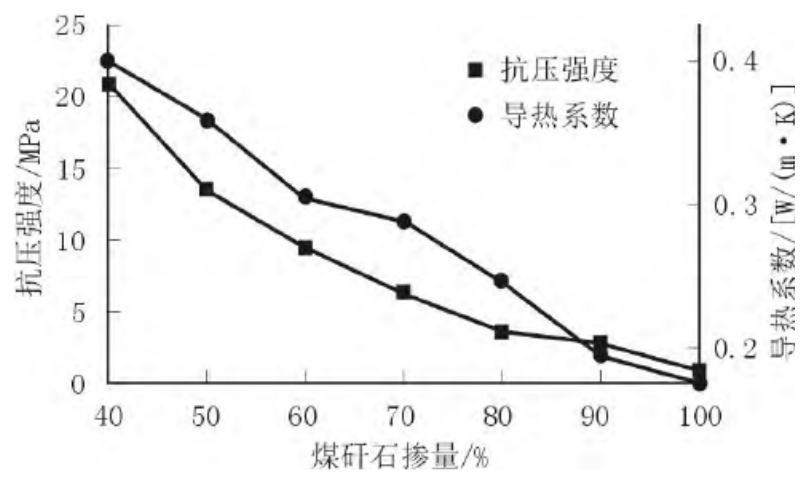

图 1 选矿废渣煤研石掺量对烧结保温砖性能的影响图

从图 1 中可以清楚看出, 随着选矿废渣煤矸石掺量的不 断增加, 保温砖的抗压强度、导热系数均不同程度下降, 究其 原因, 膨润土属于粘接剂, 随着选矿废渣煤研石掺量的提升, 膨润土用量随之降低, 从而影响了保温砖的塑性, 甚至难以 成行。通过增加膨润土可提升保温砖中二氧化硅的含量, 进 而保证砖体的强度。考虑到保温砖抗压强度和导热系数, 在 烧结保温砖时, 选矿废渣煤研石的掺量最好控制在 $60 \%$ 左右, 此时, 烧结的保温砖抗压强度为 $9.48 \mathrm{MPa}$, 导热系数为 $0.304 \mathrm{~W} / \mathrm{m} \cdot \mathrm{K}$, 符合实际要求 ${ }^{[1]}$ 。

2.3 烧结温度对选矿废渣煤矸石保温砖性能的影响

衡量保温砖性能是否达标的因素有两个, 其一是抗压强 度, 其二是导热系数, 为达到充分满足二者要求, 在烧结保温 砖时,可采用选矿废渣煤䂥石：膨润土为 6:4 的配合比。但 
在具体烧结过程中, 为最大限度利用选矿废渣煤矸石可采用 10\%的粉煤灰代替膨润土, 控制保温砖的配比为: 选矿废渣煤 䂥石: 粉煤灰: 膨润土为 $6: 1: 3$, 原材料都要经过 60 目篮选, 成型压力控制在 $12 \mathrm{MPa}$ 之间, 当烧结温度为 $500^{\circ} \mathrm{C} 、 800^{\circ} \mathrm{C}$ 、 $900^{\circ} \mathrm{C} 、 1000^{\circ} \mathrm{C}$ 时, 保温砖的性能如表 2 所示:

表 2 不同烧成温度对煤矸石保温砖性能的影响

\begin{tabular}{|c|c|c|c|}
\hline 烧结温度 $/{ }^{\circ} \mathrm{C}$ & 抗压强度 $/ \mathrm{MPa}$ & 导热系数 $/ \mathrm{W}(\mathrm{m} ・ \mathrm{~K})$ & 密度 $/\left(\mathrm{kg} / \mathrm{m}^{3}\right)$ \\
\hline 500 & 1.35 & 0.18 & 1068 \\
\hline 800 & 1.90 & 0.32 & 1130 \\
\hline 900 & 3.42 & 0.31 & 1158 \\
\hline 1000 & 8.12 & 0.29 & 1201 \\
\hline
\end{tabular}

从表 2 中可以看出, 随着烧结温度的不同提升, 保温砖 的抗压强度和密度不断提升, 但烧结温度达到 $900^{\circ} \mathrm{C}$, 抗压强 度明显增加, 明度也随之增加, 主要原因是随着烧结温度的 不断提升, 选矿废渣煤䂥石保温砖所呈现的形态存在较大差 异, 烧结温度在 $900^{\circ} \mathrm{C}$ 以下时选矿废渣煤䂥石保温砖内部液 相比较少, 砖体的收缩也比较小, 抗压强度和密度都比较小, 超过 $900^{\circ} \mathrm{C}$ 时, 选矿废渣煤矸石、粉煤灰、膨润土之间的粘 结更加牢固, 使得保温砖体积不断收缩, 强度和密度随着增 加 ${ }^{[2]}$ 。因此, 考虑到选矿废渣煤矸石保温砖的强度和导热系 数之间的关系, 烧结时温度控制在 $900^{\circ} \mathrm{C}$ 为最佳。

\section{3 选矿废渣煤矸石烧结保温砖技术的具体应用}

3.1 保温砖孔型、尺寸确定技术

随着计算机软件技术的不断发展, 被广泛应用在各大领 域, 在选矿废渣煤䂥石烧结保温砖中, 可先采用 ANSYS 软件 对保温砖进行有限元分析计算, 通过应力学原理和传热学原 理, 对保温砖进行改造, 以最大限度上提升保温砖的质量和 性能。为实现优化设计结果的可比性, 在进行有限元分析过 程中, 要先进行保温砖的边界条件做统一处理, 再利用专业 的压力机垫板和保温砖接触面的摩擦阻力来避免保温砖发 生横向膨胀。

在《民用建筑热工设计规范》中明确规定, 凡是民用建 筑的外墙砖体, 需要结合国家设计部门和研究部门的节能计 算要求, 再经过反复调整试验, 才能进行生产加工。在选矿废 渣煤研石烧结保温砖时, 需要先确定保温砖的孔洞分布特 征、孔洞率、孔型、壁厚、砖体类型等。确保砖体材料的各 项性你都满足设计要求。

\section{2 烧结试验和烧结过程}

选矿废渣煤䂥石烧结保温砖的流程为: 挤砖机将配制好 的选矿废渣煤䂥石混合料挤出泥条, 并切割成设计砖坏, 然 后运输到烘干室进行干燥处理, 通过烧结过程中产生的余热, 进行烘干。干燥冷却和处理后, 在把砖坏在输送到轮窑进行
预热、焙烧、保温、冷却, 才能形成外观优美, 强度符合国家 烧结保温砖质量的要求 ${ }^{[3]}$ 。

当干砖坏进入烧结窑室以后, 根据其特有的内燃值调整 外燃添加量以及风门开启的位置、数量等, 保证烘干室中的 温度、风量满足选矿废渣煤䂥石烧结保温砖要求。控制焙烧 温度在 $900^{\circ} \mathrm{C}^{\sim} 1000^{\circ} \mathrm{C}$ 之间, 烧结时间控制 2 小时左右。如果 温度超过 $1050^{\circ} \mathrm{C}$, 则要立即打开火眼进行散热处理, 并提升 预热带风门, 降低空气氧气进入焙烧室的总量。如果焙烧温 度低于 $900^{\circ} \mathrm{C}$, 则要加大外燃添加量和添加的次数, 并及时调 节风量和风门的位置, 降低窑内风速, 必要时可添加一些柴 油或者木棍, 促使窑中的温度能够快速提升到设计温度。

3.3 烧结保温砖性能指标分析

选矿废渣煤研石烧结保温砖是目前建筑工程外墙施工 中常用的原材料, 其烧结方法和传统多孔烧结砖的方法基本 相同, 无需进行专业培训, 但对建筑工程外墙的保温效果而 言, 不但和保温砖的性能指标相关, 而且还要充分考虑混凝 土构件的冷热桥部门, 具有很强的系统性和综合性, 只有确 保各项材料的性能指标符合要求后, 才能从根本上外墙保温 节能的效果 ${ }^{[4]}$ 。

\section{4 选矿废渣煤研石烧结保温砖关键技术分析}

在选矿废渣煤矸石烧结保温砖中, 关键技术在于如何按 照设计单位对建筑物各个墙体的热工性能进行计算, 通过计 算机有限元软件可对选矿废渣煤䂥石烧结保温砖的空洞分 布特征、空洞率、孔型、壁厚等进行全面系统的设计, 进而 保证保温砖的质量和性能,

\section{4 结束语}

综上所述, 本文结合理论实践, 研究了选矿废渣煤䂥石 烧结保温砖技术, 研究结果表明, 利用选矿废渣煤䂥石来烧 结保温砖, 既能节约成本, 又能提升选矿废渣煤矸石的利用 率, 缓减煤炭生产中选矿废渣煤研石过于堆积污染环节和影 响居民生活的问题, 一举多得, 值得大范围推广应用。

\section{[参考文献]}

[1]刘小千.转炉渣替代铁矿选矿废渣在熟料生产中的 使用[J].水泥工程,2018,(02):45+54.

[2]张跃芝.采矿选矿废渣对预拌砂浆性能的影响[J].建 筑科技,2017,1(02):28-30.

[3]杨映塘,武学龙.采用冶金废渣生产抗硫酸盐硅酸盐 水泥的实践[J].中国建材科技,2014,23(06):19-21.

[4]徐德斌.简论六苴选矿废水废渣资源的综合利用 [J]. 有色金属设计,2013,40(04):5-8. 